\title{
FAHRENHEIT 451: \\ diálogos com a filosofia de Deleuze
}

\author{
Marcela Penaforte Fernandes
}

\begin{abstract}
Resumo
Este artigo pretende identificar na história em quadrinhos FAHRENHEIT 451, de Tim Hamilton (2019), traços da filosofia de Deleuze, tendo em vista a construção de uma linguagem da multiplicidade que envolve tecnologia e imaginário cultural. Uma experimentação que pretende ler a ficção norte-americana sob o olhar do desejo em contraste com uma sociedade de controle. O conhecimento como ameaça ao assujeitamento na esteira do pensamento sem imagem, da criação dentro do universo marcado pela transitoriedade. $\mathrm{O}$ livro como recurso de combate à máquina despótica. $\mathrm{O}$ fogo dos bombeiros como signo da ordem. Apontamentos que constatam as ações de liberdade e opressão numa dada sociedade do controle.

Palavras-chave: Deleuze. Ficção. Desejo. Máquina despótica. Linguagem.
\end{abstract}

\footnotetext{
* Professora de Inglês da rede municipal de Ibirité-MG. Graduada em Letras Português/Inglês pela Pontifícia Universidade Católica de Minas Gerais (PUC Minas/2008). Mestre em Estudos de Linguagens pelo Centro de Educação Tecnológica de Minas Gerais (CEFET-MG/2019) | Belo Horizonte, Brasil. ORCID: https://orcid.org/0000-0001-5948-2161.
}

Cadernos CESPUC de Pesquisa. Série Ensaios. n.37, $2^{\circ}$ Sem./2020, p. 236-248. e-ISSN: 2358-3231 (OJS). Recebido em: 20/08/2020. Aceito em: 19/10/2020. 


\title{
FAHRENHEIT 451: \\ Dialogues With Deleuze's Philosophy
}

\author{
Marcela Penaforte Fernandes
}

\begin{abstract}
This article aims at investigating in FAHRENHEIT 451, comics written by Tim Hamilton (2009), signs of Deleuze's philosophy, considering the building of a multiplicity language that involves technology and cultural imaginary. An experiment that aims to read this North-American fiction under the gaze of desire in contrast to a society of control. Knowledge as a threaten to the system composed by those who serves, analyzed by the concepts of thought without image, of creation inside the universe marked by transience. The book as a resource for fighting againist the despotic machine. Firemen's fire as a sign of order. Notes that note the actions of freedom and oppression in a given society of control.
\end{abstract}

Keywords: Deleuze. Fiction. Desire. Despotic machine. Language. 
(...) quem escreve termina por gerar um fluxo que não se completa naquele que lê, mas, ao contrário disso, está sempre à espera de uma nova conexão, de um novo olhar que lhe permita continuar em movimento. É assim que um escrito, seja ele de ficção ou de filosofia, é algo que não se fecha em si mesmo, mas precisa sempre de uma força externa para manter-se "vivo" (SCHÖPKE, 2012, p. 21).

Passando por uma noção de transitoriedade, o pensamento, construído por meio da criação de conceitos, é a potência do estudo de Gilles Deleuze e Félix Guattari, sendo a palavra "movimento" parte dessa filosofia que propõe uma forma de ler o mundo sob o olhar da diferença, da "quebra dos limites" (SCHÖPKE, 2012, p. 21). Nesse sentido, em contato com a nota introdutória do autor Ray Bradbury é possível perceber que sua forma de se relacionar com a arte acontece por meio de um movimento que deixa o "subconsciente (...) correr sem limites" (HAMILTON, 2019, p. 7). Esse fluxo de imaginação como expressão da produção bradburyana, torna reconhecido e valorizado seu trabalho que foi escrito no período pós Segunda Guerra Mundial, obra que denunciou a opressão anti-intelectual nazista, o autoritarismo imposto à sociedade. Essa ficção norte-americana pensa um futuro no qual o conhecimento passa a ser controlado. A destruição do conhecimento tem seu ápice no hábito da queima de livros, tendo em vista coibir a potência crítica de um povo instruído. Isso representa uma ameaça ao Estado, razão pela qual na Utopia de Bradbury, retratada por Tim, só é permitida a leitura de manuais para operar aparelhos ${ }^{1}$. Nesse ponto, essa proposta de leitura lança reflexões diante dos cruzamentos com as abordagens contemporâneas de uso da linguagem, problematizando as noções que não reconhecem o aspecto múltiplo da prática linguageira, tanto no âmbito interacional presencial quanto dentro da cultura digital e busca tecer uma análise que se constrói nas vias da descontinuidade, da incompletude, do indizível.

Considerando essa linha de escrita que está vinculada ao fluxo da imaginação, interessa pensar o FAHRENHEIT 451 com os conceitos

1 A descrição inserida nesta parte está baseada na publicação do site da EDITORA SARAIVA. Disponível em: <https://www.saraiva.com.br/fahrenheit451-nova-ortografia-4087766/p >. Acesso em: 17 ago. 2020. 
guattaro-deleuzianos a partir de uma leitura que se constrói pelo "caos", "lugar onde todas as determinações se desvanecem" (SCHÖPKE, 2012, p. 23), pelas "linhas de fuga", caminhos em vias desconhecidas, passagem para territórios como permanente "tornar-se" e "desfazer-se" que se "desenham ou se apagam" (DELEUZE; GUATTARI, 1992, p. 117).

A história em quadrinhos de Hamilton se desenvolve em três partes, sendo a primeira "a lareira e a salamandra", uma introdução de histórias que apontam para o estranhamento que é produto de um deslocamento, uma mudança de direção pela qual passará o bombeiro Guy Montag e tem seu "acontecimento" em um encontro com a vizinha Clarisse McClellan, uma observadora. Se por um lado Montag, o queimador de livros, defendia os interesses do sistema e agia comandado pelo quartel, de outro, se deparava com a presença "maluca" da moça que caminhava ao seu lado na rua (HAMILTON, 2019, p. 15). As conversas dos personagens podem ser associadas ao "caosmo" guattaro-deleuziano, caos + cosmos, linha conceitual na qual as coisas distintas se relacionam o tempo todo.

Dessa forma, na personagem Clarisse é possível ler traços guattaro-deleuzianos da filosofia da diferença pela produção de um pensamento que é "molecular", ou seja, que é livre-desorganizante pela afirmação do desejo. Querendo questionar a vida, a personagem se faz multiplicidade ao se descolar das coisas fixas para se abrir a uma violência livre e afirmativa. Mediante a moça, seu deslocamento corporal e livre, Montag pensa: "o quão raro era o rosto de outra pessoa tomar sua expressão e lançá-la de volta sobre você, seus mais profundos pensamentos trêmulos?" (HAMILTON, 2019, p. 21). Clarisse é o signo, a violência, que fará Montag voltar a ver. Pois, "fazia muito tempo que Montag não olhava" (HAMILTON, 2019, p. 18), sua capacidade de observar, de fazer alguma coisa por conta própria, estava cada vez mais comprometida pela estampa da "máquina despótica" (DELEUZE; GUATTARI, 2004). O serviço profissional de repressão, por um certo período, tornava o bombeiro cada vez mais próximo da moral, da razão, da busca por "corpos dóceis", trabalhando o assujeitamento que pretende adequar o desejo. Neste ponto, a queima dos livros é resultado de uma sociedade do controle em seu grau máximo. Quando controla a

\footnotetext{
2 A expressão é um conceito de Deleuze e Guattari utilizado para falar sobre uma estrutura que busca a lei, que alimenta o capitalismo.

3 Conceito guattaro-deleuziano que trata da condição de submissão, imposição de um sistema que regula o desejo que é produção constante, que é vida em movimento.
} 
subjetividade, a queima dos livros é uma das consequências arbitrárias da sociedade do controle.

A inquietude de Clarisse desperta em Montag um olhar que o faz enxergar o desejo que é revolucionário: "Ele vestia sua felicidade como máscara, e a garota havia roubado e fugido com a máscara e não havia como pedi-la de volta" (HAMILTON, 2019, p. 22). Neste sentido, Montag, desvinculando-se do desejo gangrenado, domesticado, parecia entender que: “(...) como ruptura, como descontinuidade, a diferença não pode ser representada sem se tornar uma inimiga do pensamento, isto é, o elemento perturbador de uma ordem 'previamente' estabelecida" (SCHÖPKE, 2012, p. 23, grifo do autor). Dessa forma, essa quebra de paradigmas se coloca em relação de oposição ao que o capitão Beatty, chefe do corpo de bombeiros, observa quando comenta sobre um aluno odiado pela turma por ser "brilhante": "Não são todos nascidos iguais e livres, como a Constituição diz, mas todos são feitos iguais” (HAMILTON, 2019, p. 58).

Nesse caso, se tem uma completa homogeinização, eliminação da diferença. Em via inversa está a noção metafísica da semelhança que fica então evidente em uma fala que está impregnada com o formato, o molde, com tudo que nega a existência da diferença, pois, nesta concepção, não há espaço para o entendimento da singularidade guattaro-deleuziana, que é igual a pluralidade, uma vez que se considera a imagem do pensamento de Platão, que é algo pronto para se seguir. Contrariamente, Deleuze e Guattari propõem o pensamento sem imagem, ou seja, do "simulacro" (SCHÖPKE, 2012 , p. 55), daquilo que não tem cópia, algo que precisa ser criado a todo momento e que acontece de forma incerta. Nesses termos, a base da filosofia platônica (fundamento) é questionada diante da transgressão da diferença que ressoa na própria natureza:

Como falar em repetição, se a chuva que cai todos os dias, em uma mesma hora, não é nunca a mesma chuva? Como dizer que as gotas de orvalho, caídas no dia de hoje, poderão se repetir amanhã, se cada gota é única e só poderá retornar se transgredir as leis da natureza? É isso que Deleuze quer mostrar: quando a ciência fala em repetição, está falando apenas da passagem de uma ordem de generalidade a uma outra ordem de generalidade (...). A repetição é sempre "transgressora" uma vez que ela vai em direção contrária às leis que impedem qualquer coisa de retornar (SCHÖPKE, 2012, p. 35, grifo do autor). 
O trecho acima pode ser lido como parte do processo que desmonta o pensamento do senso comum que pertencia a Montag: o "prazer especial [de] ver as coisas serem consumidas (...) ver as coisas enegrecidas e transformadas", posicionamento que queria se impor com o fogo da lei que "destrói responsabilidades e consequências. Um problema se torna grande demais? Então para a fornalha com ele" (HAMILTON, 2019, p. 11; 117).

Nesse sentido, sentir o perfume como querosene (capacidade que Clarice tem) é um rastro da brutalidade de um sistema que exige farejadores para combater a "máquina de guerra"4 que aproveita das fissuras da "máquina despótica” para desestabilizá-la (DELEUZE; GUATTARI, 2004). Diferentes do "cão mecânico", uma "incrível invenção que nunca contém um erro", réplicas eram produzidas no quartel, bombeiros convencidos de que são "garotos da felicidade (...) contra a pequena maré daqueles que querem deixar todo mundo infeliz com teorias e pensamentos conflitantes" (HAMILTON, 2019, p. 125; 137; 59). Os pensamentos conflitantes são aqueles que geram o pensamento mesmo, razão pela qual o pensamento do conflito, os "patinhos feios" no dizer do capitão Beatty, chefe do corpo de bombeiros, eram eliminados pelos bombeiros que, com o fogo, eram treinados para queimar qualquer "bomba relógio" como Clarisse, posto que "Ela não queria saber como se fazem as coisas, mas por quê" (HAMILTON, 2019, p. 59). Esse ímpeto polêmico, na lógica da moral do Estado, se configura como sendo motivo de infelicidade, de confusão.

Em razão disso, a polícia aparece como o caminho da segurança, mas em Deleuze e Guattari, seria uma vigilância periculosa, que distorce as forças afirmativas da vida. Ao categorizar como insano quem "acha que pode enganar o governo e a gente [bombeiros - queimadores de livros]" o jogador do quartel põe as cartas do baralho e suas palavras na mesa. $\mathrm{O}$ capitão, "imóvel gado da maioria", era signo da distorção da palavra "febre", diagnóstico oferecido para quem se perguntava assim como Montag passou a fazer: "como continuar queimando as coisas?" (HAMILTON, 2019, p. $41 ; 108 ; 112)$. O questionamento de Montag aponta para o processo de transformação, de transvaloração dos valores, pelo qual este personagem estava passando.

O jogo é desafiador e arde como a febre diante da indignação de ser agente e testemunha de uma ignorância que é alheia aos que assumem ser

4 Conceito de Deleuze e Guattari que tira o fundamento e coloca tudo em movimento; vale dizer que o termo não é usado no sentido bélico. 
"ovelhas que já se desviaram uma vez ou outra" (HAMILTON, 2019, p. 104). Montag, opondo-se a todo esse esquema aprisionador, experimentando o paradoxal e desejando com o grupo de livros assegurar que o conhecimento não morra, participa de uma guerra: a luta agora é contra os "queimadores de livros", então companheiros de trabalho de Montag.

Esse rompimento de Montag com o modelo vigente, momento no qual o personagem passa a assumir uma nova forma de viver, não mais contra os livros, mas com os livros, é abordado na "Parte dois: a peneira e a areia". Esse trânsito de Montag vem dos agenciamentos, das forças que estão operando em determinado socius (sociedade), que não comportam mais a domesticação da população, o caráter repressivo dentro das instituições, o pensamento único. Nessa fase, como ser pensante, Montag reprova o bem que os bombeiros dizem fazer para o povo e se torna "esquizo"5 ao se manifestar como produtor do desejo que está em uma lógica fora das regras (condutas), e em vias moleculares ${ }^{6}$ que tentam tirar a ordem aprisionante das coisas.

Com a explosão desse novo jeito de ver as coisas, Montag passa a ser perseguido pelos seus pares e a experiência da fuga é desenrolada no capítulo final, "ardendo intensamente". Os defensores dos livros, desejando mantê-los vivos e presentes na vida das pessoas, decidiram decorar aquele conteúdo, na intenção de que um dia os livros pudessem ser "escritos novamente" (HAMILTON, 2019, p. 153). A violência gerada pelo contato com a leitura apostava na oralidade para um dia conseguir passar para $o$ papel o que estava sendo posto em chamas.

As oposições ao violento sistema de controle do conhecimento passam por uma movimentação da imaginação que é uma potência percebida por Nietzsche como pertencente aos "seres do desejo cuja vontade afirmativa quer sempre dar outra vez uma chance a possibilidades novas de vida e de interpretações" (DUMOULIÉ, 2005, p. 156). Montag e os outros personagens interessados nos livros, como corajosos guerreiros, agem agora em nome de um combate travado por uma minoria: os caçadores de bombeiros. Do outro lado do sistema, fazem um papel bem diferente

\footnotetext{
5 Esse conceito guattaro-deleuziano não remete ao estado clínico de uma pessoa, mas àquele que está em desconformidade com o padrão da normalidade muitas vezes requerido pela sociedade, valorizando assim, sua capacidade de criar, de imaginar, de explorar o mundo de maneiras não convencionais. 6 Molecular é um conceito guattaro-deleuziano que evidencia o movimento constante das coisas. Está em oposição ao molar, que seria o ponto fixo, que tem fundamento, base.
} 
do que costumavam desempenhar. A essa altura da narrativa, Montag, reconhecido como inimigo do Estado passa a ser caçado, e

a polícia sugere que toda a população na área de Elm Terrace faça o seguinte: cada pessoa em cada casa de cada rua abra uma porta da frente ou dos fundos ou olhe pela janela. O fugitivo não pode escapar se todos no próximo minuto olharem de suas casas (HAMILTON, 2019, p. 140).

Ao fugir dos oficiais, Montag para de compactuar com a "máquina despótica" que o deixou cego diante dos acontecimentos abusivos dirigidos ao povo que temia os bombeiros. Dessa forma, para desenvolver essa questão da troca de valores, vale reproduzir a pergunta de Clarisse: "É verdade que no passado os bombeiros apagavam o fogo em vez de começá-lo?”. Ainda encharcado dos pretextos que rondam os servidores da "máquina despótica", Montag responde: "Não, as casas sempre foram à prova de fogo, acredite em mim" (HAMILTON, 2019, p. 16). Sua fala põe à mostra alguém que provavelmente nunca questionou as ordens que recebeu por falta de vontade ou mesmo medo, mas que executou os serviços com fidelidade.

O ponto escuro do diálogo de Montag e Clarisse, os confrontos e deslocamentos, tudo isso só tornou as coisas mais complexas para o bombeiro, que começa então a se sentir incomodado com o que faz e se preocupa com os prejuízos que a sociedade pode ter com a ação dos queimadores de livros. Nesse ponto, Montag assume a condição de "nômade" no sentido guattaro-deleuziano, sendo estrangeiro na sua própria terra na medida em que explora territórios de maneira inédita, nas imediações do "devir"8.

Esse novo olhar de Montag o torna alvo da polícia. Porém, esse personagem se sente "Em súbita paz... longe da cidade e das luzes, longe de tudo" (HAMILTON, 2019, p. 143). Em uma possível leitura, essa cena de Montag, imerso nas águas geladas do rio, seria a própria tentativa de ruptura dele com a sujeira da "máquina despótica". Essa alusão ao que Heráclito disse sobre a impossibilidade de alguém banhar-se mais de uma vez num mesmo rio traz a noção do novo guattaro-deleuziano como algo que grudou ao personagem e que, nesse mergulho, tornou-se evidente.

\footnotetext{
7 Conceito que vem da filosofia guattaro-deleuziana que diz sobre aquele que se faz estrangeiro na terra onde habita, que luta por aquilo que deseja e vive sob o ângulo da desestabilidade proporcionada pelo "devir".

8 Conceito de Deleuze e Guattari que trabalha o inesperado, aquilo que não pode ser planejado, que está para acontecer; sem rastros.
} 
O choque do "devir" em contraste com a vida programada que Montag levava; as atribuições do bombeiro e as percepções de cada parte da história: combatentes, suspeitos/acusados. O jeito oficial de dar notícias e circular informações. Toda essa trama foi possível pelo pensamento que Montag se permitiu experimentar. Do outro lado, procurado pelos oficias, o personagem é dado como morto para mostrar que a vingança do crime contra a sociedade aconteceu, mas tiveram cuidado para não mostrar "o rosto do homem de perto" (HAMILTON, 2019, p. 147).

Confirmando a existência de outros lutadores do conhecimento, o personagem Montag declara que estão espalhados, "abandonados", e que são: "maltrapilhos por fora, bibliotecas por dentro" (HAMILTON, 2019, p. 152). Outro sinal da inversão de valores sociais que impede o povo de enxergar o que tem valor afirmativo.

Dessa forma, nas cenas finais, a detonação da cidade que virou poeira deixa no ar o poder do império da "máquina despótica" que remove do caminho o que pode atrapalhar sua expansão e marca o desejo gangrenado de fazer desaparecer tudo que existia ali. A menção às "cidades mortas" ao redor do mundo seria uma percepção permitida pela "máquina de guerra" que entende a morte neste caso como a inexistência do conhecimento (HAMILTON, 2019, p. 155). O ser pensante ocupa seu lugar na sociedade de forma diferente e imprevisível, pois está disposto a questionar as coisas, mesmo que para isso, seja necessário sair do status pacífico e causar "transtornos".

Quando em uma sociedade, esvaziada de pessoas, em meio aos destroços, um personagem reconhece que, na ocasião em que tinham os livros em mãos, eles não eram valorizados com a devida atenção, isso é um indício de que a "máquina despótica" está sob a mira de um ataque. Nesse ponto de solidão, eles iriam dizer aos que encontrassem (o que parece um exercício banal, mas é altamente revolucionário): "estamos nos lembrando" (HAMILTON, 2019, p. 156).

Sem embargos, o ato de lembrar está vinculado ao esboroamento da sociedade do controle que está vinculado à vizinhança de Montag com Clarisse. O bombeiro passa por caminhos novos e observa mais as coisas, dialogando, assim, com o pensamento guattaro-deleuziano. Esse tempo para questionar fez o personagem passar de uma margem à outra do rio, como se lê na citação final: "E de cada lado do rio havia uma árvore da 
vida... que carregava doze tipos de frutas, e dava frutos todos os meses... e as folhas das árvores eram para a cura das nações" (HAMILTON, 2019, p. 157).

A aparente rotina da natureza tem nas águas o reflexo do novo ser que olha sem inocência, e observa o que poucos podem enxergar. O movimento da cena pode provocar o leitor em relação à noção de previsibilidade (colheita) e ao poder de cura presente bem ali, nas folhas das árvores. A ordem que um dia foi possível admitir converte-se pelo conhecimento crítico que se adquire nos livros e, dessa forma, subverte a ordem despótica. A paisagem já alterada pela radical explosão de intolerância dos guerreiros da "máquina despótica" constitui-se num devir desses e, sendo opressor, nega a multiplicidade, conforme Deleuze e Guattari, chocando-se com a "máquina de guerra" toda vez que alguém tenta desconstruir suas influências.

Como a folha da árvore que discretamente se faz cura para as nações, as folhas dos livros podem curar da doença da ignorância. Os frutos como alimento do desejo do conhecimento são expressão da "máquina de guerra" que nunca alcança uma saciedade de experimentar e se movimenta pelas águas do "devir". Por outro lado, a sociedade de controle aproveita o fruto de uma forma limitada e deseja impor ao povo uma forma pronta, finalizada de degustar. Nesse ponto, a concepção de vida em cada sistema se diferencia e os seres fazem suas escolhas que podem ou não estar voltadas para o lado fértil da vida.

Os quadrinhos podem servir como estímulo ao pensamento livre por tratar criticamente dessa sociedade de controle opressora que deseja dominar todos os territórios, usando diversos artifícios para iludir o povo e o privar dos momentos de pensar sem imagem, ou seja, de forma criativa. $\mathrm{O}$ livro como arma de guerra, traz o conhecimento como ameaça aos padrões sociais vigentes. Sem o pensamento crítico, trabalhando para manter o povo submisso e esgotando sua energia, poucos inconvenientes surgirão pelos caminhos do controle.

Pensando no uso da linguagem na contemporaneidade, nas possibilidades de interação intencionais e/ou espontâneas, nas camadas sociais e nos propósitos de comunicação, o texto ficcional vale como provocação ao que se entende por construir relações por meio da comunicação. Observando vários aspectos que garantem o tom vivo da língua, importa destacar alguns deles aqui: dicionários adaptados 
expressando as necessidades emergentes de comunicação, o uso das mídias sociais e as novas implicações da forma de se gerar texto oral e escrito, a questão dos livros digitais, os materiais impressos, a oralidade. Erguem-se com esse viés da vivacidade da língua o aspecto dinâmico e o movimento infinito que atravessam a linguagem. Descolar do caráter previsível, regular que paira sobre fundamentos de ordem gramatical, seria a abertura para esse canal de comunicação da experimentação que gera sensações que as palavras apenas pretendem explicar. Certamente não existe aqui pretensão de negligenciar as normas formais da língua, mas focar naquilo que os usuários experimentam ao utilizar a comunicação que está em constante fluxo, tal como se dá no processo de criação de vocabulário para as necessidades emergentes (pode-se listar aqui o que vem do universo tecnológico, o conteúdo gerado pelas mídias sociais). Nesse sentido, vale pensar na confusa concepção da língua como um objeto de decodificação, como se tudo estivesse ali aguardando uma oportunidade para acontecer. No entanto, essa lógica ignora a complexidade existente na atividade de enunciação justamente por não admitir a existência de um movimento que a atualiza e potencializa. A força que passa nesse canal da comunicação está na esteira do inapreensível perante o novo que a cada instante inaugura posto ainda que se torna impraticável admitir um único jeito de se pensar o mundo, de interagir com o que está diante de nós.

Retomando a escolha dos quadrinhos de Tim Hamilton (2009) para desenvolver o tema da multiplicidade presente na linguagem, é oportuno destacar que os falantes evidenciam esse caráter espontâneo da língua no lugar do modo automático, programado como parece estar posto em certos manuais gramaticais com exemplos que, de alguma maneira, impõem limites às possibilidades inesgotáveis de uso da língua. Uma dessas aberturas seria o controle. A capacidade de usar a língua para impor ordens, para acusar, para distorcer fatos, para fabricar acontecimentos. Os personagens ficcionais vivem esse entremeio: convicções por um lado, incertezas de outro. O mundo que se descortina é inexplorado e a linguagem está como signo de poder. A muralha da ameaça passa a estar nas letras que transbordam dos livros. $\mathrm{O}$ valor do contato com a leitura em contraste com os ideais do sistema de controle. $\mathrm{O}$ choque de quem entende o que pode acontecer com a oferta do conhecimento e o impacto da parte que deseja reprimir esse potencial da imaginação, da criação. Fazendo um paralelo com o hoje em 
dia, o conhecimento está sob ataque, necessariamente pela banalização do discurso científico, pela valorização de formas coloquiais e fraudulentas de circular notícias.

Com a praticidade do universo digital, o convívio a distância está em conexão imediata com as realidades das pessoas e os impactos da comunicação afetam positiva e negativamente todo tipo de público. Os estragos sociais como na ficção são imensuráveis. A propaganda das promessas do mundo tecnológico, a criação da necessidade de se fazer contato por meio de ferramentas de comunicação virtual, gera uma dependência de uma linguagem que sugere uma trama criativa que, por vezes, trabalha a linguagem como instrumento de manipulação, de controle. O conteúdo nocivo que poda a natural multiplicidade da linguagem constrói uma sociedade vigiada por forças que pensam a língua na produção de pensamento com imagem, afugentando a sua exponente geração do pensamento sem imagem, ou seja, da criação que está em construção e não acabada. A filosofia de Deleuze e Guattari longe de pretender resolver questões, se constitui como possibilidade de saída para se combater as violências do sistema de controle, considerando o poder da imaginação que permite pensar de maneira nova, criar saídas diferentes diante de cada problema que surge.

Tendo em mente a marca da multiplicidade presente na linguagem os quadrinhos de Tim Hamilton (2009) corroboram com as análises propostas neste artigo por trazer a temática da perseguição ao conhecimento dentro de um sistema de controle que entende os riscos que o ser pensante oferece para a estrutura do próprio esquema social, no dizer Deleuze e Guatttari, "máquina despótica”. Agir na contramão desse sistema dominante é causar desordem e liberar o pensamento sem imagem, dando espaço às faculdades da imaginação, da criação. $O$ constante movimento pertencente a esse processo de fabulação pode desorientar, exatamente por não estar preso a nenhuma fórmula, por ser algo da ordem do imprevisível. Entendendo que esses conceitos filosóficos provocam um novo olhar sobre as práticas de linguagem, compensa refletir sobre as formas de se utilizar a comunicação e os reflexos disso na vida social. $O$ fechamento à noção da variedade seria o preço a se pagar pelo sossego de um caminho que se configura com autonomia de imposição. Contrariamente, estão as vias intocáveis da multiplicidade, dos caminhos do porvir. 
Desconstruindo concepções rígidas sobre a prática da linguagem, a partir dos levantamentos aqui apontados, espera-se que caminhos do diálogo na esteira da interdisciplinaridade aconteçam, novas pesquisas sejam realizadas para que se possa, pela aproximação, problematização, cruzamento de saberes, alcançar benefícios para a condição existencial humana necessariamente pelo empenho em se perceber como ser da multiplicidade. Assim, uma proposta intrigante se põe com a leitura dessa história: como cada ser instruído que tem acesso aos livros está promovendo transformações afirmativas por onde passa? Os desafios dos bombeiros revolucionários dialogam com os que os pensadores têm na atualidade. Perseguições, repressões: tudo se torna uma questão de resistência para sustentar as convicções de quem alimenta a imaginação e se propõe a fazer leituras novas ainda que em contato com o mesmo material.

\section{Referências}

DELEUZE, Gilles; GUATTARI, Félix. O anti-édipo: capitalismo e esquizofrenia 1. Tradução de Joana Moraes Varela e Manuel Maria Carrilho. Lisboa: Assírio e Alvim, 2004. [E-Book]. Disponível em: <http:// conexoesclinicas.com.br/wp-content/uploads/2015/12/DELEUZEGilles-GUATTARI-F\%C3\%A9lix.-O-Anti-\%C3\%89dipo-vers\%C3\%A3oPortugal1.pdf>. Acesso em: 20 ago. 2020.

DELEUZE, Gilles; GUATTARI, Félix. O que é a filosofia?. Rio de Janeiro: Editora 34, 1992, 288 p.

DUMOULIÉ, Camille. O desejo. Camille Dumoulié; tradução de Ephraim Ferreira Alves. - Petrópolis, RJ: Vozes, 2005, 327 p.

SCHÖPKE, Regina. Por uma filosofia da diferença: Gilles Deleuze, o pensador nômade/Regina Schöpke. - 1 reimpr. - Rio de Janeiro: Contraponto, 2012, 219 p.

TIM, Hamilton. FAHRENHEIT 451/Adaptação de Tim Hamilton; tradução de Felipe CF Vieira. - São Paulo: Excelsior - Book one, 2019, 160 p. 